\title{
Factors influencing the reproductive health of women in rural areas of Ujjain, Madhya Pradesh
}

\author{
Nikita Srivastava, Navya Vyas*, Prakash Narayanan, P. Arathi Rao
}

Department of Public Health, Prasanna School of Public Health, Manipal Academy of Higher Education, Manipal, Udupi, Karnataka, India

Received: 14 July 2018

Accepted: 06 August 2018

*Correspondence:

Dr. Navya Vyas,

E-mail: navya.vyas@manipal.edu

Copyright: () the author(s), publisher and licensee Medip Academy. This is an open-access article distributed under the terms of the Creative Commons Attribution Non-Commercial License, which permits unrestricted non-commercial use, distribution, and reproduction in any medium, provided the original work is properly cited.

\section{ABSTRACT}

Background: A woman's health is an integral part of any country. There are numerous factors that influence a woman's decision of her reproductive health. A better understanding of these factors could help address gaps and barriers influencing the reproductive health choices of women in rural areas.

Methods: A community based cross-sectional study was carried out among women of ages 18-45 years in rural areas of Ujjain, Madhya Pradesh to study factors influencing the reproductive health choices of women in rural areas of Ujjain. 300 women were asked comprehensively about their reproductive health via a semi structured questionnaire which comprised of domains from their menarche history to their menopausal history. Data was analyzed and chi square test was used to find factors influencing the reproductive health choices of women.

Results: The median age of the participants was 30.8 years (IQR: 25,36 ). Around $61 \%$ of the participants were aware of the family planning methods but only $29 \%$ of the participants used modern contraceptive methods. Age, educational background of participants, employment, partner education were all factors significantly $(p<0.05)$ associated with the reproductive health choices of women.

Conclusions: The reproductive health of women was shown to be significantly associated with her education, her employment status, her age, and her partner's education. Therefore, it is important to raise awareness among women, their partners and, the family members about importance of the reproductive health of a woman.

Keywords: Antenatal care, Female sterilization, Modern contraceptive methods, Post-natal care, Reproductive health

\section{INTRODUCTION}

Every day, approximately 830 women die from preventable causes related to pregnancy and child birth ${ }^{1}$ Maternal death tops the deaths in the developing countries and is high among women living in the poor communities of the rural areas. ${ }^{1}$

Women who undergo their first pregnancy around the age of 18-21 years contribute to a higher percentage of these deaths. Majority of them die due to the complications resulting during/following pregnancy and child birth. Most of these diseases are preventable and treatable but the lack of income, distance from the health care facility, lack of awareness, and the cultural practices women are not receiving and seeking care.

Many of these health care facilities near the villages are either underequipped or lack skilled workers. ${ }^{1}$ In 2015 , births in the richest 20 per cent of households were more than twice as likely to be attended by skilled health personnel as those in the poorest 20 per cent of households. ${ }^{1}$ Women do not receive or do not attain full antenatal care visits. ${ }^{1}$ Maternal Mortality is higher in rural areas and among poorer and less educated communities in developing countries like India. Home deliveries by 
midwifes is a cultural norm in rural areas of India since it's a common belief that it's a natural phenomenon and it does not require medical attention and should be conducted at home.

However, it is not just the cultural belief but poverty, illiteracy, and ignorance regarding the complications of delivery that contribute to a lot of women in India delivering at home. ${ }^{2}$

Additionally, women in rural areas of India do not access antenatal care services because of the socio-economic and health factors. In India, according to National Family Health Survey (NFHS) 4, more than three-quarters of pregnant women received at least some antenatal care, but only half of the women had received at least three ANC visits as prescribed mandatory by the government norms of ANC in India. ${ }^{3}$

Similarly, in Ujjain, literacy rate among woman accounts for $58.6 \%$ and woman with 10 more years of schooling is just about $20.7 \%$.

Mothers who have had complete antenatal checkups account for just $40.5 \%$. Only $19.1 \%$ consumed folic acid for 100 days or more during pregnancy and $56.1 \%$ are receiving complete postnatal care. Female sterilization in Ujjain is $26.1 \%$ whereas male sterilization is $0.2 \% .^{4}$

As for District Level Household Survey 3 (DLHS3) majority $(38.3 \%)$ of the women do not go to health institutions for delivery reporting that they do not have time to go or do not find it necessary to go due to the lack of awareness among the women and her family members.

Also $74.9 \%$ women discussed reproductive tract infection/ sexually transmitted infections problems with their husbands/ partners but women who sort treatment for these are just $30.3 \% .^{5}$ The data above suggests that reproductive health is very poor in Ujjain.

Therefore, it is important to understand relationship of the reproductive health of women with various biological and socio-economic factors like age, sex, educational level, occupation, income and expenditure of the household, family size, religion, etc.

The study was carried out to understand the role of sociodemographic factor's contribution to the reproductive health choices of a women in rural areas.

Studying these factors would help address the barriers and gaps in the utilization of services and implement measures to improve the reproductive health of women.

The study would contribute to bring critical reproductive health services to millions of women living in low income areas and address factors that are contributing to the choices women make about their reproductive health.

\section{METHODS}

The study was a community based cross-sectional study carried out in rural areas of Ujjain district in, Madhya Pradesh from January 2018 to June 2018. All women in 18-45 years of age in the household who had ever been married and have given birth were eligible to participate in the study. Sample size was calculated considering 57.7 $\%$ as the percentage of pregnant women who had one or more living children with respect to a study carried out in Jamnagar and was considered as the anticipated proportion. ${ }^{6}$

The total sample size of the study was calculated to be 300. The list of villages was attained from the District Health officer and 20 villages in Nagda Tehsil were selected through simple random sampling procedure.

The list of women of ages 18-45 years who have given birth was obtained from the ASHA worker of each village. The participants were then numbered. A random number table was generated using excel where 15 participants were selected from each village.

The study was initiated after approval from the Institutional Ethical Committee was obtained. The participants were provided with information about the study by the principal investigator and were informed that their participation in the study was solely voluntary. Informed written consent was obtained from the participants. Participants were then asked comprehensively about their reproductive health.

The questionnaire was validated. It included the following domains; socio-demographic characteristics, menstrual cycle and menstrual hygiene details, obstetric history of each pregnancy, antenatal care history of each pregnancy, delivery details, postnatal care history of each pregnancy, family planning and contraceptive use, history of reproductive tract infections used in their lifetime, menopausal history, and healthcare facility details.

\section{Statistical analysis}

Data was analyzed using SPSS15. The categorical variables were expressed in frequency and percentage and the continuous variable in median and interquartile range (IQR). Chi-Square test was performed to find the associations. A p-value $<0.05$ was considered to be statistically significant.

\section{RESULTS}

The study had a total sample size of 300 participants. The median age of participants was 30 years (IQR: 25, 36). Among the participants, 123 (41\%) had no formal education, $44 \%$ were semi-skilled workers working in agricultural fields or lifting bricks at construction sites, and $40 \%$ were homemakers. Majority of the participants 
were Hindus and currently married, and 54\% were from joint families. This is depicted in Table 1.

Table 1: Socio-demographic characteristics of the study participants $(n=300)$.

\begin{tabular}{|c|c|c|}
\hline Variables & Categories & $\begin{array}{l}\text { Frequency } \\
\text { n }(\%)\end{array}$ \\
\hline \multirow{4}{*}{ Age (years) } & $18-24$ & $59(19.667)$ \\
\hline & $25-31$ & $124(41.333)$ \\
\hline & $32-38$ & $55(18.333)$ \\
\hline & $>38$ & $62(20.667)$ \\
\hline \multirow{5}{*}{$\begin{array}{l}\text { Educational } \\
\text { background }\end{array}$} & Uneducated & $123(41.000)$ \\
\hline & Primary school & $85(28.333)$ \\
\hline & Middle school & $55(18.333)$ \\
\hline & High school & $36(12.000)$ \\
\hline & Graduate & $1(0.333)$ \\
\hline \multirow{2}{*}{ Religion } & Hindu & $296(98.667)$ \\
\hline & Muslim & $4(1.333)$ \\
\hline \multirow{3}{*}{ Marital Status } & Married & $289(96.333)$ \\
\hline & Separated & $2(0.667)$ \\
\hline & Widow & $9(3.000)$ \\
\hline \multirow{3}{*}{ Family Type } & Joint family & $161(53.667)$ \\
\hline & Nuclear family & $133(45.667)$ \\
\hline & Single parent family & $5(1.667)$ \\
\hline \multirow{6}{*}{$\begin{array}{l}\text { Occupational } \\
\text { Profile }\end{array}$} & Arithmetic skill jobs & $27(9.000)$ \\
\hline & Semi-professional & $1(0.333)$ \\
\hline & Semi-skilled worker & $132(44.000)$ \\
\hline & Skilled-worker & $19(6.333)$ \\
\hline & Unskilled worker & $1(0.333)$ \\
\hline & Homemakers & $120(40.000)$ \\
\hline
\end{tabular}

Table 2 illustrates the socio-demographic factors influencing the utilization of antenatal care services and postnatal care services. $93 \%$ of the participants attended antenatal care and $84 \%$ of the participants had some postnatal care. Significant association was found between the socio-demographic variables age, educational background, employment status, number of children, and partner education ( $p$ value <0.05). This implies that educated women less than 31 years old and who are working are more likely to utilize antenatal and postnatal services when compared to uneducated older women without jobs.

Furthermore, the education of the participant's husband played a significant role in the utilization of antenatal and postnatal care services. Women with educated partners were more likely to attend antenatal and postnatal care when compared to partners who had no education.

Lastly, women with 1-3 pregnancies were more likely to attend antenatal care and postnatal care when compared to women with 4-6 pregnancies. The use of modern family planning method was significantly associated with the educational background of the participants and their husband. This implies that education of both the partners plays a significant role in the utilization of modern contraceptive methods. Female Sterilization on the other hand, was seen to be significantly associated with the participant's age, educational background, employment, family type, and the number of children. Women older than or equal to 31 years old and no education were more likely to undergo female sterilization when compared to younger and educate women. Furthermore, women working and living in nuclear families were more likely to undergo sterilization when compared to women at home and living in joint families. Lastly, the number of children contributed significantly to the choice of undergoing female sterilization. Women with 1-3 children were more likely to have undergone female sterilization when compared to women with 4-6 children. This is depicted in Table 3.

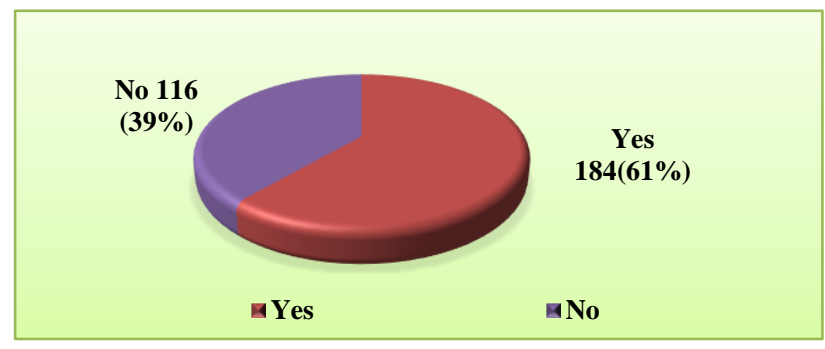

Figure 1: Distribution of participants with respect to the awareness of family planning methods.

As illustrated in Figure 1 and Figure 2, majority $(61.333 \%)$ of the study participants were aware of family planning methods but only $29.000 \%$ participants were utilizing modern contraceptive methods. Additionally, female sterilization was observed to be significantly associated with the age, educational background of the participant, and the no of children.

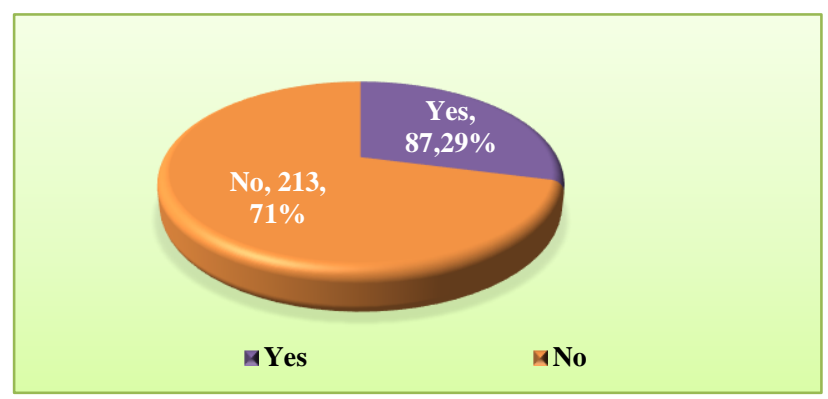

Figure 2: Distribution of participants with respect to the use of modern family planning methods.

Older and uneducated study participants were more likely to undergo sterilization when compared to younger and educated women; older and uneducated women reported being unaware of other family planning methods when compared to the younger and educated women. Participants who had children between the ages of 1-3 were more likely to undergo female sterilization when compared to participants with 4-6 children. This was depicted in Table 3. 
Table 2: Relation of demographic factors with utilization of antenatal care and postnatal care services.

\begin{tabular}{|c|c|c|c|c|c|}
\hline Domains & Variables & Categories & Yes, n (\%) & No $\mathrm{n}(\%)$ & p-value \\
\hline \multirow{14}{*}{ Antenatal care } & \multirow{2}{*}{ Age } & $<31$ years & $175(61.837)$ & $2(11.765)$ & \multirow{2}{*}{0.002} \\
\hline & & $\geq 31$ years & $108(38.163)$ & $15(88.235)$ & \\
\hline & \multirow{2}{*}{$\begin{array}{l}\text { Educational } \\
\text { background }\end{array}$} & Uneducated & $109(38.516)$ & $14(82.353)$ & \multirow{2}{*}{0.014} \\
\hline & & Educated & $174(61.484)$ & $3(17.647)$ & \\
\hline & \multirow{2}{*}{ Employment } & Working & $168(59.364)$ & $12(70.5888)$ & \multirow{2}{*}{0.993} \\
\hline & & Not working & $115(40.636)$ & $5(11.765)$ & \\
\hline & \multirow{2}{*}{ Family type } & Nuclear & $132(46.643)$ & $7(41.176)$ & \multirow{2}{*}{0.072} \\
\hline & & Joint & $151(53.357)$ & $10(58.824)$ & \\
\hline & \multirow{2}{*}{ Number of children } & 1 to 3 & $182(64.311)$ & $5(29.411)$ & \multirow{2}{*}{0.005} \\
\hline & & 4 to 6 & $101(35.689)$ & $12(70.588)$ & \\
\hline & \multirow{2}{*}{$\begin{array}{l}\text { Number of } \\
\text { pregnancies }\end{array}$} & 1 to 4 & $258(91.166)$ & $14(82.353)$ & \multirow{2}{*}{0.204} \\
\hline & & $5-8$ & $25(8.834)$ & $3(17.647)$ & \\
\hline & \multirow{2}{*}{ Partner education } & Uneducated & $57(20.141)$ & $8(47.059)$ & \multirow{2}{*}{0.015} \\
\hline & & Educated & $226(79.858)$ & $9(52.941)$ & \\
\hline \multirow{14}{*}{ Post-natal care } & \multirow{2}{*}{ Age } & $<31$ years & $163(67.355)$ & $14(24.137)$ & \multirow{2}{*}{0.001} \\
\hline & & $\geq 31$ years & $79(32.644)$ & $44(75.862)$ & \\
\hline & \multirow{2}{*}{$\begin{array}{l}\text { Educational } \\
\text { background }\end{array}$} & Uneducated & $91(74.000)$ & $32(26.000)$ & \multirow{2}{*}{0.017} \\
\hline & & Educated & $151(85.333)$ & $26(14.667)$ & \\
\hline & \multirow{2}{*}{ Employment } & Working & $136(56.198)$ & $44(75.862)$ & \multirow{2}{*}{0.007} \\
\hline & & Not working & $106(43.802)$ & $14(24.138)$ & \\
\hline & \multirow{2}{*}{ Family type } & Nuclear & $109(45.000)$ & $30(51.667)$ & \multirow{2}{*}{0.284} \\
\hline & & Joint & $133(55.000)$ & $28(48.333)$ & \\
\hline & \multirow{2}{*}{ Number of children } & 1 to 3 & $161(66.529)$ & $26(44.828)$ & \multirow{2}{*}{0.004} \\
\hline & & 4 to 6 & $81(33.471)$ & $32(55.172)$ & \\
\hline & \multirow{2}{*}{$\begin{array}{l}\text { Number of } \\
\text { pregnancies }\end{array}$} & $1-4$ & $219(90.496)$ & $53(91.379)$ & \multirow{2}{*}{1.000} \\
\hline & & $5-8$ & $23(9.504)$ & $5(8.621)$ & \\
\hline & \multirow{2}{*}{ Partner education } & Uneducated & $47(19.421)$ & $18(31.034)$ & \multirow{2}{*}{0.015} \\
\hline & & Educated & $195(80.579)$ & $40(68.966)$ & \\
\hline
\end{tabular}

Table 3: Factors influencing use of modern family planning methods among study participants and female sterilization.

\begin{tabular}{|c|c|c|c|c|c|}
\hline Domains & Variables & Categories & Yes n $(\%)$ & No n $(\%)$ & p-value \\
\hline \multirow{14}{*}{$\begin{array}{l}\text { Use of modern } \\
\text { contraceptive methods }\end{array}$} & \multirow{2}{*}{ Age } & $<31$ years & $53(61.6279)$ & $123(57.746)$ & \multirow{2}{*}{0.604} \\
\hline & & $\geq 31$ years & $33(38.372)$ & $90(42.253)$ & \\
\hline & \multirow{2}{*}{ Educational background } & Uneducated & $13(15.116)$ & $109(51.173)$ & \multirow{2}{*}{0.001} \\
\hline & & Educated & $73(84.883)$ & $104(48.836)$ & \\
\hline & \multirow{2}{*}{ Employment } & Working & $50(58.139)$ & $130(61.032)$ & \multirow{2}{*}{0.696} \\
\hline & & Not working & $36(38.967)$ & $83(38.967)$ & \\
\hline & \multirow{2}{*}{ Family Type } & Nuclear & $34(39.535)$ & $105(49.065)$ & \multirow[b]{2}{*}{0.159} \\
\hline & & Joint & $52(60.465)$ & $109(50.935$ & \\
\hline & \multirow{2}{*}{ No. of pregnancies } & 1 to 4 & $57(66.279)$ & $129(60.563)$ & \multirow{2}{*}{0.827} \\
\hline & & 5 to 8 & $29(33.720)$ & $84(49.436)$ & \\
\hline & \multirow{2}{*}{ No. of children } & 1 to 3 & $79(91.860)$ & $192(60.563)$ & \multirow{2}{*}{0.429} \\
\hline & & 4 to 6 & $29(33.720)$ & $84(39.4366)$ & \\
\hline & \multirow{2}{*}{ Partner education } & Uneducated & $8(12.333)$ & $57(87.667)$ & \multirow{2}{*}{0.001} \\
\hline & & Educated & $78(33.222)$ & $157(66.778)$ & \\
\hline \multirow{14}{*}{ Female sterilization } & \multirow{2}{*}{ Age } & $<31$ years & $73(48.344)$ & $104(69.798)$ & \multirow{2}{*}{0.001} \\
\hline & & $\geq 31$ years & $78(51.656)$ & $45(30.201)$ & \\
\hline & \multirow{2}{*}{ Educational background } & Uneducated & $81(53.642)$ & $42(28.188)$ & \multirow{2}{*}{0.001} \\
\hline & & Educated & $70(46.357)$ & $107(71.812)$ & \\
\hline & \multirow{2}{*}{ Employment } & Working & $107(70.861)$ & 73 (48.993) & \multirow{2}{*}{0.001} \\
\hline & & Not working & $44(29.139)$ & $76(51.007)$ & \\
\hline & \multirow{2}{*}{ Family type } & Nuclear & $81(53.642)$ & $59(38.926)$ & \multirow{2}{*}{0.01} \\
\hline & & Joint & $70(46.357)$ & $91(61.064)$ & \\
\hline & \multirow{2}{*}{ No. of pregnancies } & 1 to 4 & $81(53.642)$ & $106(71.140$ & \multirow{2}{*}{0.321} \\
\hline & & 5 to 8 & $70(46.357)$ & $43(28.859)$ & \\
\hline & \multirow{2}{*}{ No. of children } & 1 to 3 & $134(88.741)$ & 138 (92.617) & \multirow{2}{*}{0.002} \\
\hline & & 4 to 6 & $17(11.258)$ & $11(7.382)$ & \\
\hline & \multirow{2}{*}{ Partner education } & Uneducated & $39(25.828)$ & $26(17.450)$ & \multirow{2}{*}{0.093} \\
\hline & & Educated & $112(74.172)$ & $123(82.550)$ & \\
\hline
\end{tabular}




\section{DISCUSSION}

The study was designed to analyze the reproductive health of women in rural areas of Ujjain and to find factors that influence the reproductive health choices of women. Majority of the participants were in the age group of 25-31 years old and were uneducated. However, majority of them were semi-skilled workers. Furthermore, the study revealed that educational background, employment, age, family type, number of pregnancies, type of delivery, and number of children have been factors significantly associated with the reproductive health of a woman.

The study indicated a significant association of antenatal care with educational background, employment status, and age of the study participants. Younger educated women who were working were more likely to attend ANC while compared to older and uneducated women without jobs. Furthermore, women with educated partners were more likely to attend ANC when compared to participants with uneducated partners. Participants reported that since their partners were educated they would encourage them and take them to the hospital for regular checkups during pregnancy.

The study also indicated that women with less children were more likely to use ANC services when compared to women with more children. A similar study conducted in Nepal also revealed that women in the age group of 19-25 years and 26-30 years were more likely to receive ANC care when compared to women older than 30 years of age. The utilization of antenatal care services was significantly associated with the age of the women at last child birth, religion, castes was also observed. ${ }^{7}$ Furthermore, a study carried out in Ethiopia revealed similar findings where a woman's education level, employment status, and age of mothers was significantly associated with the use of antenatal care services. ${ }^{8}$

A similar pattern was observed for the utilization of postnatal care services. The study indicates that younger women were more likely to receive postnatal care while compared to women $\geq 31$ years. Educated $(56.2 \%)$ and employed women were more likely to receive postnatal care when compared to illiterate and unemployed women since literate and employed women were more aware of the services. Older participants reported that during the time when they were pregnant services were not available, and if they were they were either too far away or they did not understand the importance of postnatal care. Majority of the participants received postnatal care only twice that too during their stay in the hospital after their delivery. Some participants reported that they would be sent back home the same day after their delivery.

However, ASHA workers would come home for postnatal care. Also, educated partners of the participants encouraged them to attain postnatal care after delivery when compared to uneducated partners. Participant's reported that their partners who were educated would inform ASHA workers about the delivery and encourage them to visit for a regular checkup. Also, participants with 1-3 children were more likely to attend postnatal care when compared to participants with 4-6 children.

A study carried out in Nepal depicted that household wealth status, maternal education, maternal occupation, paternal education and paternal occupation were significantly associated with the postnatal care attendance. ${ }^{9}$ A study conducted in Ethiopia expressed that place of delivery was one of the strongest predictors of postnatal care service utilization. ${ }^{8}$

The study revealed that majority $(61.333 \%)$ of the participants were aware of the different family planning methods, however only $29.00 \%$ of the participants were utilizing modern contraceptive methods. Participants reported that they were not comfortable using modern contraceptive like contraceptive pills because they were scared that it would lead to infertility. Some reported that their husbands were not willing to use condoms and that is why female sterilization was their choice of contraception.

However, the use of modern contraceptive methods was significantly associated with the educational background of the study participant and her husband. Educated participants discuss about modern contraceptive methods with their partners and educated partners also suggest the use of contraceptive pills to their wives. Increase in the education raises the likelihood to use contraception than among those without education. Similarly, in a study conducted in Malda District in West Bengal, it was observed that education level of the women has a highly significant effect on awareness and use of contraceptive methods. It was observed the educated women would freely discuss the contraceptive options with their partners. ${ }^{10}$

Female sterilization remains the most popular modern contraceptive method in India. According to the NFHS4 data, among the currently married women age 15-49, $36 \%$ use female sterilization. ${ }^{3}$ In this study, 151 (50.333) study participants had undergone female sterilization, among which $91.389 \%$ had undergone tubectomy. Age, educational background, type of family, employment, and the number of children had expressed significant association with female sterilization. Older and uneducated women were more likely to undergo female sterilization when compared to women who were younger and educated.

Older women during the course of the study reported that they were not aware of other family planning methods and the ones they knew were either not effective or they were not allowed to use the same since their husbands and in laws did not consent. Also, the women reported that their parents in law believed that since husbands need to do more physical work a male sterilization 
surgery will make them weaker therefore is it preferred a woman undergo female sterilization. Women working and living in nuclear families were more likely to undergo female sterilization when compared to women who were homemakers, because women working believed that if they would be pregnant it would make it difficult for them to work also if they are at work no one would be taking care of the children at home.

Also, women with 1-3 children were more likely to have undergone female sterilization when compared to women with 4-6 children reporting that they had undergone female sterilization as soon as they delivered a baby boy, and women with 4-6 children were continuing pregnancies to be able to bare a baby boy.

A study carried out in Raichur revealed similar findings. $61.43 \%$ of participants were unaware of male sterilization. On the other hand, women who were aware of male sterilization still opted for tubectomy because they believed that if a male undergoes vasectomy and the surgery fails, it will have an impact on the family economy, as he is the earning member. Also, the study revealed that husbands are the decision makers of the family and expresses male dominance when option for tubectomy. ${ }^{11}$

\section{CONCLUSION}

To conclude, socioeconomic factors like age, education, and economic backgrounds play a crucial role in maintaining the health of a woman. Number of children and number of pregnancies also contribute in the decisions a woman makes about her reproductive health.

Educated and young women were more likely to avail health care services when compared to older and uneducated women. One of the major reasons being that today there is an increased awareness about these services and that it is now easier to attain health care facilities because they have become affordable due to the schemes that have been implemented by the government.

Henceforth, socio-cultural aspects that affect and shape reproductive health motivations and behavior are important in understanding key issues in the utilization of services more effectively and in assessing the gaps in knowledge, concepts and notions relating to reproductive health.

To be able to do this, there is a need to increase awareness via health education camps for family planning methods and utilization of antenatal and postnatal care services among women, their partners, and their family members. Also, a qualitative study can be conducted in depth to have a better understanding on the reasons and barriers in accessing care, information on sensitive cultural factors affecting reproductive health and also information on gender preferences.

\section{ACKNOWLEDGMENTS}

Authors would like to express sincere thanks to District Health Officer, Ujjain District, to all the faculty members of Masters in Public Health, Prasanna School of Public Health, Manipal Academy of Higher Education, Manipal, to all the participants and the ASHA workers for the support during the study.

Funding: No funding sources

Conflict of interest: None declared

Ethical approval: The study was approved by the Institutional Ethics Committee

\section{REFERENCES}

1. Maternal mortality. World Health Organization. 2018. Available at: http://www.who.int/en/newsroom/fact-sheets/detail/maternal-mortality

2. Ravi RP, Kulasekaran RA. Does socio-demographic factors influence women's choice of place of delivery in rural areas of Tamilnadu state in India. Am J Public Health Res. 2014;2(3):75-80.

3. International Institute of Population Sciences and ORC Macro. National Family Health Survey-4: national Fact Sheet. Available at: http://rchiips.org/NFHS/pdf/NFHS4/India.pdf

4. International Institute of Population Sciences and ORC Macro. National Family Health Survey-4: State Fact Sheet. Available at: http://rchiips.org/nfhs/FCTS/MP/MP_FactSheet_435 _Ujjain.pdf

5. International Institute for Population Sciences (IIPS), 2010. District Level Household and Facility Survey (DLHS-3), 2007-08: India. Available at http://rchiips.org/NFHS/FCTS/MP/MP_FactSheet_4 35_Ujjain.pdf

6. Unadkat SV, Yadav S, Mehta JP, Parmar DV, DHadul KM. Demographic characterstics and Reproductive Profile of pregnant Women in Jamnagar District. Natl J Community Med. 2013;4(3):418-23.

7. Kakati R, Barua K, Borah M. Factors associated with the utilization of antenatal care services in rural areas of Assam, India. Int J Comm Med Pub Heal. 2016 Dec 24;3(10):2799-805.

8. Assefa E, Tadesse M. Factors related to the use of antenatal care services in Ethiopia: application of the zero-inflated negative binomial model. Women Health. 2017 Aug 9;57(7):804-21.

9. Khanal V, Adhikari M, Karkee R, Gavidia T. Factors associated with the utilisation of postnatal care services among the mothers of Nepal: analysis of Nepal demographic and health survey 2011. BMC Women's Health. 2014 Dec;14(1):19.

10. Hussain N. Demographic, socio-economic and cultural factors affecting knowledge and use of contraception differentials in Malda district, West Bengal. J Community Med Health Edu. 2011;1(102):2. 
11. Talaab R. A study on socio-demographic and cultural factors influencing women undergoing laparoscopic tubectomy in laparoscopic tubectomy camps conducted at UHTC, AAM. Indian J Forens Comm Med. 2017 Jan; 4(1):32-6.
Cite this article as: Srivastava N, Vyas N, Narayanan P, Rao PA. Factors influencing the reproductive health of women in rural areas of Ujjain, Madhya Pradesh. Int J Reprod Contracept Obstet Gynecol 2018;7:3707-13. 